\title{
TEMPORAL BONE IMAGING IN UNILATERAL SEVERE TO PROFOUND SNHL.
}

\author{
Hassan Wahba*, Lobna El Fiky*.Wafaa ElKholy**, Samer Ibrahim* \\ Tougan Taha Abd EI Aziz*** and Radwa Helmy.
}

*Department of otolaryngo-
logy, **audiology, and ***
radiology, Ain-Shams
University Faculty of
Medicine, Cairo, Egypt
Corresponding author:
Radwa Helmy
Mobile: 01067756643
E mail:
radwa.h.ameen@gmail.com

Received: 22/4/2019

Accepted: 23 /5/2019

\begin{abstract}
:
Background: The effect of unilateral sensor ineural hearing loss (UHL) on the quality of life is well documented. Studies found a direct link between UHL and educational and social delays. Radiological studies aimed to detect the associated anomalies of the earen countered a wide variation in the rates of incidence.
\end{abstract}

Aim of the work: Our study aims to detect and give an estimate about the rate of incidence of different anomalies.

Patients and methods: A review of the medical records of Audiology department in Eldemerdash hospital between 2014 to 2017 was done. Only cases with severe to profound USNHL diagnosed before age of 12 years were included. Clinical examination, full audiological assessment, MRI and CT temporal bone were done for all cases and results were reviewed for each patient.

Results: 50 cases were included (8 cases with severe USNHL and 42 cases with profound USNHL). The mean age of diagnosis was 7.6 years.Only16 cases (32\%) had risk factors known to contribute to SNHL. The most common abnormality found was cochlear nerve (CN) deficiency in 22 cases (44\%).Bilateral findings were present in 4 cases (8\%).

Conclusion: Radiological evaluation is not only for detection of the cause but also allows proper counselling and exploring the possible options of rehabilitation.

Key words: unilateral hearing loss, pediatric hearing loss, USNHL, imaging in hearing loss, congenital SNHL, CN deficiency.

\section{INTRODUCTION:}

Severe to profound USNHL means that one ear doesn't give a serviceable hearing. In Egypt, both the absence of a functioning screening system and the patients' preference to depend on the better hearing ear instead of seeking medical advice, makes the determination of the incidence of pediatric USNHL difficult. Using temporal bone imaging, the detected incidence of inner ear anomalies in pediatric USNHL ranges between $25 \%$ and $58 \%$. $^{1-8}$

History taking and full examination should be done as SNHL can be caused by abnormalities on the cellular level which couldn't be detected by imaging techniques. ${ }^{9}$ Recently, cochlear implant is proposed as a treatment to restore binaural hearing in these patients which entails proper anatomical to decide the possibility of surgery and the possible outcome in those cases.

\section{PATIENTS AND METHODS:}

We included 50 cases of severe to profound USNHL. Inclusion criteria was unilateral severe to profound SNHL with first audiological diagnosis of HL before the 


\section{Hassan Wahba, et al.,}

age of 12 years. Excluded subjects were cases with mild and moderate degrees of hearing loss in the affected ear, bilateral HL, conductive component in HL and asymmetrical HL also cases whose age of diagnosis was after 12 years and individuals with history of ear surgery were excluded. $\mathrm{HL}$ was categorized according the WHO classification as severe SNHL if hearing threshold average between $61-80 \mathrm{~dB}$ in frequencies between $500 \mathrm{~Hz}$ and $4 \mathrm{KHz}$, and more than $80 \mathrm{~dB}$ as profound. ${ }^{11}$ The normal ear should have a hearing threshold of $20 \mathrm{~dB}$ or better in all tested frequencies. Audiologic assessment was repeated twice at two different times to ensure consistent data.

Both CT and MRI were done for all cases and were reviewed by radiologist blinded to the laterality of HL. In order to overcome the gender, age and environmental exposure the normal hearing ear was used as the control.

MRI was performed as internal auditory canal (IAC) protocol 1.5-T scanner. The caliber of the cochlear nerve $(\mathrm{CN})$ was compared to the facial nerve, the superior and inferior vestibular nerves, and the $\mathrm{CN}$ in the normal hearing side. The $\mathrm{CN}$ was described to be hypoplastic when it appeared smaller in size compared with the other nerves of the IAC. The $\mathrm{CN}$ was considered aplastic when it could not be visualized in all planes.

Non-contrast CT temporal was done with the cuts $1 \mathrm{~mm}$ wide. The protocol included axial, coronal planes with oblique sagittal reconstruction plane. Under Sennaroglu's classification, the inner ear malformation is divided into 8 categories, while the $\mathrm{CN}$ anomalies were described as a separate anomaly. ${ }^{12}$

\section{RESULTS:}

This study involved 50 subjects. Their ages at the time of evaluation ranged from 4 to 12 years, with mean age of 7.6 years \pm 2.4, while the median age was 7 years. Sixteen patients $(32 \%)$ had risk factors known to contribute to SNHL. (Table 1).Physical examination of all cases was unremarkable. None of them had history of vertigo, tinnitus or other associated neuropathies.

Table (1): Risk factors assessment for hearing loss.

\begin{tabular}{|l|c|c|}
\hline Cases & Number & Percentage \\
\hline No risk factors & 34 & $68 \%$ \\
\hline with risk factors & 16 & $32 \%$ \\
\hline$\bullet \quad$ Perinatal insults & 6 & $12 \%$ \\
\hline$\bullet \quad$ Consanguinous marriage & 4 & $8 \%$ \\
\hline$\bullet \quad$ Familial history for HL & 4 & $8 \%$ \\
\hline$\bullet \quad$ Viral infection & 2 & $4 \%$ \\
\hline
\end{tabular}




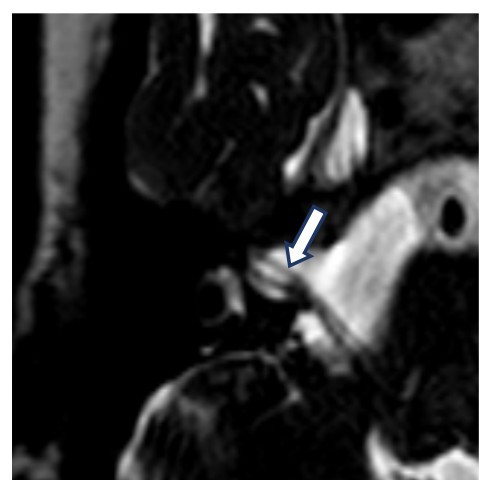

(a) Normal nerve

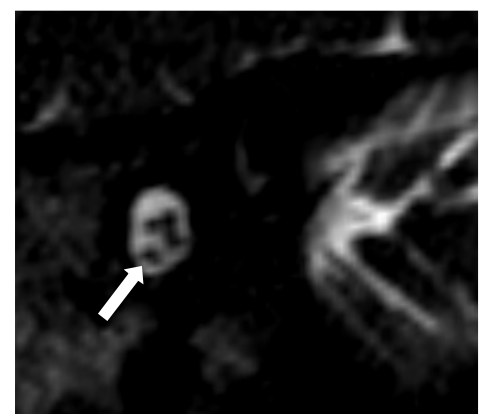

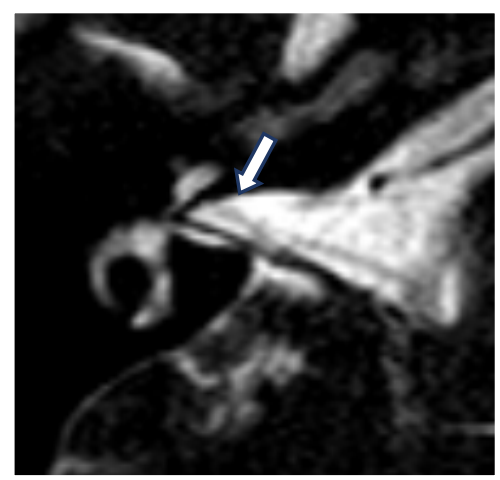

(b) Hypoplastic nerve

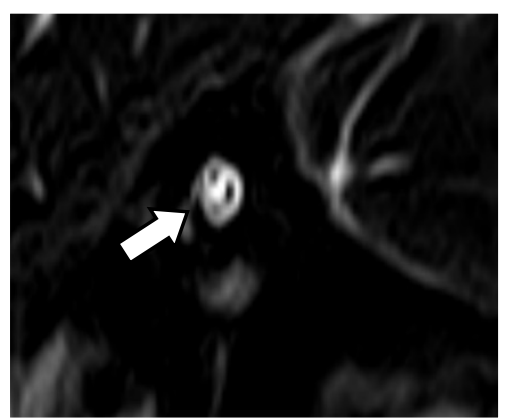

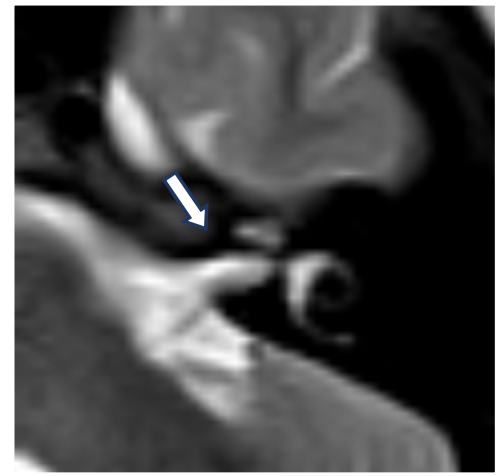

(c) Aplastic nerve

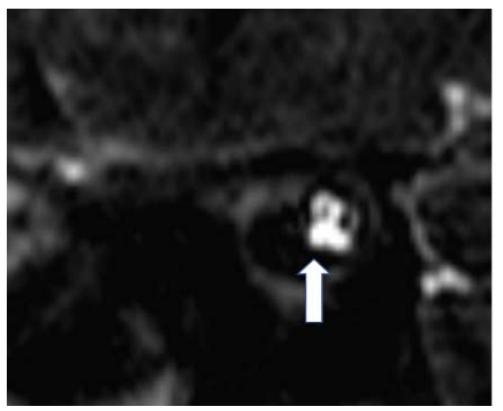

Fig (1): MRI axial and oblique sagittal cuts

Twenty-four cases were normal in both CT and MRI while 36 of them had anomalies detected in either or both imaging. The anomalies were either isolated or associated with other anomalies.

The most common was $\mathrm{CN}$ deficiency in 22 cases. Dysplastic cochlea and enlarged vestibular aqueduct (EVA) were each detected in 4 cases. All 4 cases with EVA were found associated with $\mathrm{CN}$ deficiency; furthermore, IP2 was found in 2 of them. All cases had normal IAC, SCC, vestibule. (Table 2).Bilateral $\mathrm{CN}$ deficiency present in $8 \%(n=4)$ with the affected side smaller than the other but both are smaller compared to the facial nerve.

Table (2) MRI findings in the affected ear

\begin{tabular}{|l|c|c|}
\hline Affected ear & NO. & $\%$ \\
\hline cochlear nerve (CN) & 28 & \\
Normal & 16 & 36 \\
Hypoplastic & 6 & 12 \\
Aplastic & 46 & 92 \\
\hline Cochlea & 4 & 8 \\
Normal & & \\
Dysplastic & 46 & 92 \\
\hline vestibular aqueduct & 4 & 8 \\
Normal & & \\
Enlarged (EVA) & 2 & 4 \\
\hline Cochlea and nerve abnormality & 2 & 4 \\
Normal nerve and dysplastic cochlea & 4 & 8 \\
Abnormal nerve and dysplastic cochlea &
\end{tabular}




\section{Hassan Wahba, et al.,}

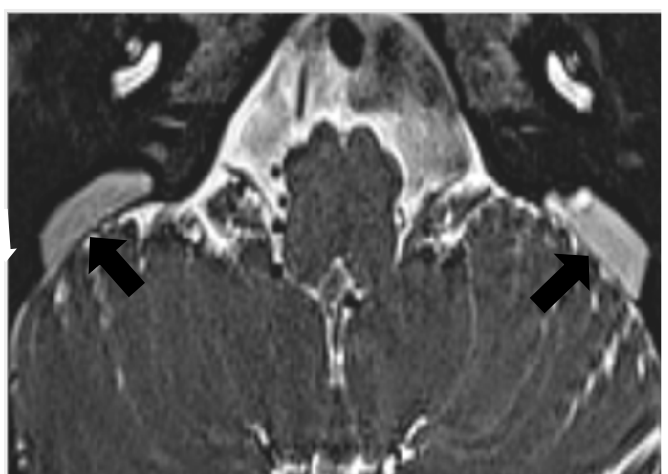

(a) bilat EVA and IP2

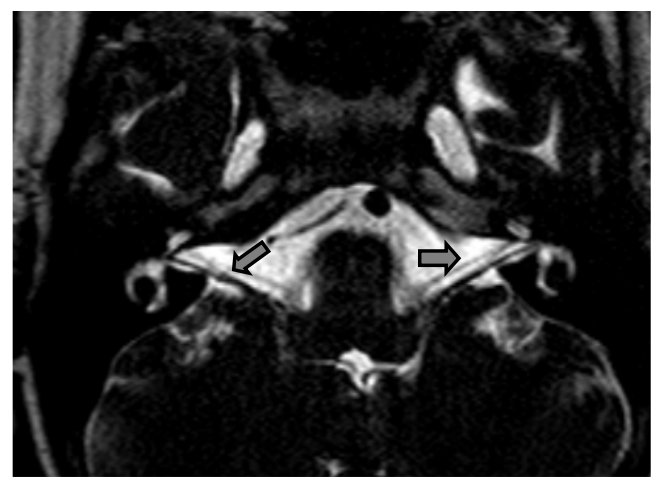

(b) CN hypoplasia

Fig (2) MRI axial cuts

CT identified anomalies in 8 cases (16\%) regarding the deaf ear. Bony cochlear nerve canal (BCNC) anomalies represent $(8 \%)$ of the affected cases. It was found completely occluded in 1 case with absent
$\mathrm{CN}$ and hypoplastic modiolus in MRI. A stenotic canal was found in 3 cases with hypoplastic nerve. Dysplastic cochlea as IP2 and EVA were each found in 2 cases (4\%)(Table 3).

Table (3) abnormal CT findings in the affected ear

\begin{tabular}{|l|c|c|}
\hline & NO. & $\%$ \\
\hline BCNC & & \\
Normal & 46 & 92 \\
Abnormal & 4 & 8 \\
\hline Cochlea & & \\
Normal & 48 & 96 \\
Dysplastic & 2 & 4 \\
\hline Vestibular aqueduct & & \\
Normal & 48 & 96 \\
Enlarged & 2 & 4 \\
\hline
\end{tabular}

MRI was superior in diagnosis inner ear anomalies, it identified $100 \%$ of anomalies while CT identified only 50\%. (Table 4). CN deficiency present in 22 cases in MRI but $63.6 \%$ of them (14 cases) had normal CT findings.

Table (4) The sensitivity of CT to MRI in diagnosis of abnormality

\begin{tabular}{|l|c|c|}
\hline & Cochlear anomalies & Vestibular aqueduct anomalies \\
\hline MRI & 8 cases $(100 \%)$ & 4 cases $(100 \%)$ \\
\hline CT & 4 cases $(50 \%)$ & 2 cases $(50 \%)$ \\
\hline
\end{tabular}



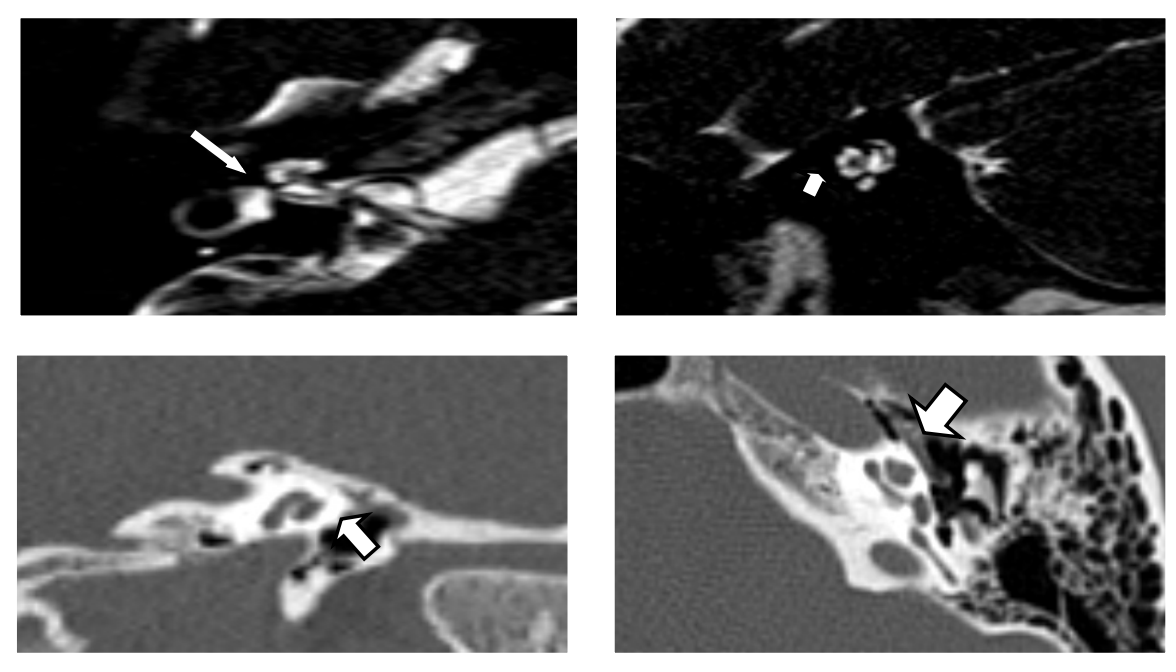

Fig (3): IP 2 in both CT and MRI

\section{DISCUSSION:}

The age of detection of USNHL is crucial for early diagnosis and intervention. Also, it plays a key role in identification of the possible cause of HL. Many studies evaluated the screening systems in their countries, and all concluded that the mean age of diagnosis decreased significantly after newborn screening system was introduced. ${ }^{13}$, 14. It was reported to be between 1 and 3.7 years of age. ${ }^{3,15,16}$ In our study, the mean age of diagnosis was 7.6 years \pm 2.4 . This is probably due to lack of primary neonatal screening in Egypt. The screening allows an accurate diagnosis of the cause of hearing loss. Prior to screening, the most common etiology was idiopathic $41 \%$ followed by congenital factor $27 \%$ and other risk factors $22 \%$. After screening, there was a shift in percentage of different etiologies. Congenital factors became the most common etiology $45 \%$ followed by idiopathic $31 \% .{ }^{17}$ In $68 \%$ of our cases, no evident etiology could be found, while the perinatal period events, familial history of $\mathrm{HL}$, consanguineous marriage and viral infections were $12 \%, 8 \%, 8 \%$ and $4 \%$ respectively. The high incidence of idiopathic cases may be attributed to lack of proper documentation during the perinatal period as we rely only on history taking which might be deficient in some points.

Many inner ear anomalies could be detected by MRI as a single modality. In comparison with CT; MRI is more accurate in delineating the inner ear structures. ${ }^{9}$ The detected incidence of inner ear anomalies in pediatric USNHL ranges between $25 \%$ and $58 \%$, where the most common positive finding was $\mathrm{CN}$ deficiency with a rate of occurrence between $14 \%$ and $58 \% .{ }^{1-8}$ In our sample, MRI identified abnormalities in $52 \%$ of cases. The most common anomaly was $\mathrm{CN}$ deficiency $44 \%(32 \%$ had hypoplastic nerve, while $12 \%$ had an aplastic nerve). In previous studies, $\mathrm{CN}$ hypoplasia ranged between $7.1 \%$ and $42.5 \%$ while $\mathrm{CN}$ aplasia was between $11.9 \%$ and $68 \%$. $^{17,19,20,21}$

In cases with USNHL; the normal hearing ear is considered to have a normal structure by default. Recently, studies including USNHL reported bilateral lesions. While Song and colleagues ${ }^{22}$ included cases of post traumatic and post meningitis SNHL reported a rate of incidence of bilateral anomalies in $19.4 \%$ of cases using CT scan, Bamiou and colleagues ${ }^{18}$ included cases with syndromic hearing loss reported an 
incidence rate $20 \%$.'In this study, bilateral findings were present in $8 \%(n=4)$ of the cases. All had bilateral hypoplastic $\mathrm{CN}$ detected by MRI with the affected side smaller than the other but both nerves are smaller when compared to the facial and vestibular nerves. Two of them were associated with bilateral EVA and cochlear IP2. None of them had signs of an existing syndrome. This can be due to nonsyndromic genetic abnormalities.
The term of isolated $\mathrm{CN}$ deficiency means a dysplastic $\mathrm{CN}$ without any other deformity. The incidence of isolated $\mathrm{CN}$ deficiency in this study was $28 \%$. This goes with the finding of previous studies where the incidence was $27 \%{ }^{20}$

In our study, the cochlea was dysplastic in $8 \%(n=4)$ and EVA occurred in $8 \%$. All cases had normal IAC, SCC and vestibule

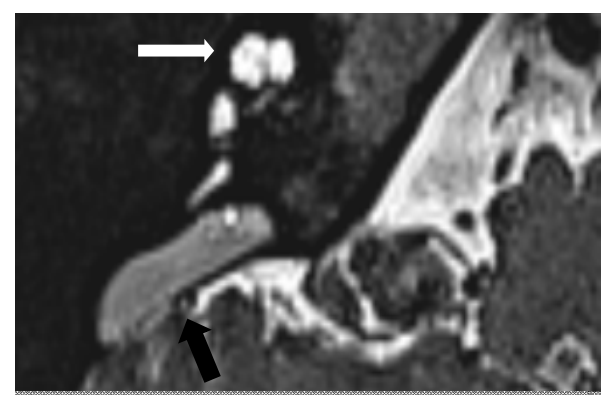

Fig (4): MRI axial cuts showing right EVA with IPII.

This is different from previous reports where the least mentioned rate of cochlear anomalies was $20.3 \%$, the incidence of EVA ranged from $4 \%$ to $75 \%$ and the reported incidence of IAC and vestibularmal format-

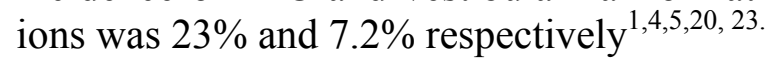

In many studies, EVA can occur as an isolated lesion but usually it is a part of a wider developmental abnormality. EVA has a wide spectrum of audiological presentation ranging from mild to profound HL. Also, it can be of sudden onset, fluctuating or progressive course. EVA can be unilateral or bilateral; when bilateral, it can cause asymmetric HL. ${ }^{4}{ }^{23-25}$ In our study, there were 2 cases of bilateral EVA with bilateral hypoplastic $\mathrm{CN}$ and bilateral IP2, who were presented only with USNHL. This presentation is not common for bilateral EVA but in routine audiological follow up for one of them, the child had a deterioration in hearing in the presumed normal ear.

Developmental venous anomalies (DVA) are the most common vascular lesion in CNS imaging. Most of them are asymptomatic or uncomplicated. It is extremely rare in the CPA and IAC. They can cause SNHL if caused compression of the CN. There were 2 case reports of DVA causing USNHL in children. Although rare, it should be considered in the differential diagnosis of USNHL. ${ }^{26-28}$ Vascular loops are a normal variant of vascularity present in $8 \%$ of cases in this study. They were bilateral with no mass effect. So, they are considered harmless.

The CT sensitivity (as a single modality) in SNHL reported by previous studies ranged between $7 \%$ and $44 \%$. ${ }^{23,22}$ Our study was within this range, where the $\mathrm{CT}$ was able to detect the possible reason of USNHL in $16 \%$ of cases.

In literature $\mathrm{BCNC}$ caliber of less than $1.4 \mathrm{~mm}$ was considered stenotic. Canal stenosis incidence was between $46.4 \%$ and $85 \%$ of congenital cases. Also, many studies found a direct connection between the width of the canal and $\mathrm{CN}$ deficiency with sensitivity up to $84 \%$ of cases. ${ }^{16,5,23,29}$ 


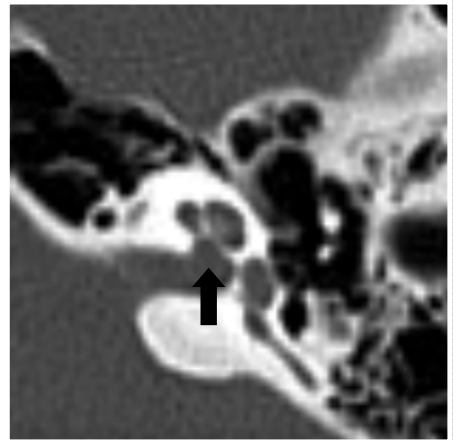

(a) Normal BCNC

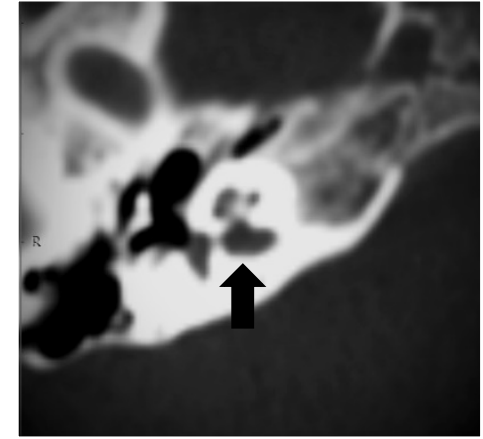

(b) stenotic BCNC

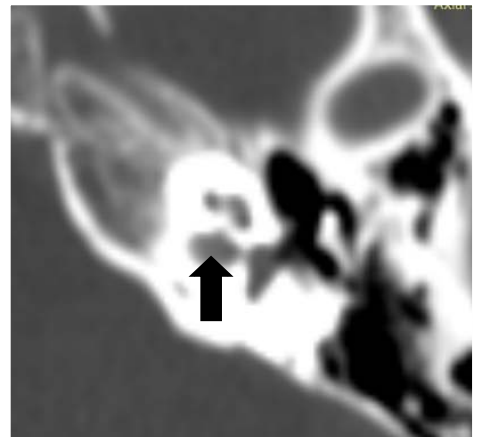

(c) occluded BCNC

Fig (5): CT axial cuts

The numbers derived from our study don't line up with this data. The incidence of BCNC anomalies was only $8 \%$ of total cases. In this study $\mathrm{CN}$ deficiency incidence was $44 \%$. But CT didn't give a hint in most cases of $\mathrm{CN}$ deficiency. All cases with BCNC anomalies had $\mathrm{CN}$ deficiency but $36 \%$ of cases with $\mathrm{CN}$ deficiency had a normal BCNC. The stenosis of BCNC can be a good indicator for $\mathrm{CN}$ deficiency. But normal BCNC doesn't indicate a normal nerve.

In 2018, Sunwoo and colleagues ${ }^{16}$ reported a $100 \%$ incidence of $\mathrm{CN}$ deficiency and $85 \%$ incidence of $\mathrm{BCNC}$ in cases of congenital SSD. Also, Masuda in $2013^{23}$ gave an incidence of BCNC anomalies of $46.4 \%$ in USNHL. This discrepancy can be owed to the type of included samples. Sunwoo depended upon cases diagnosed before the age of 1 with profound USNHL after failing neonatal screening tests and excluded cases with apparent risk factors for HL, Masuda depended on a similar sample but didn't exclude cases with risk factors which gave an incidence of BCNC anomalies of $46.4 \%$. A study in 2010 used a sample of children with auditory neuropathy (AN). They reported an incidence rate of $81.6 \%$ for $\mathrm{BCNC}$ anomalies and $\mathrm{CN}$ deficiency. ${ }^{30}$ This is because they included cases diagnosed as AN, whom, by default have an audiometric evidence of normal cochlear function and thus, will probably have a normal cochlea in imaging. So, these findings cannot be generalized.

Degeneration of the cochlear nerve theory can explain the absence of the $\mathrm{CN}$ without any other anomaly. The nerve gradually degenerates, and the $\mathrm{CN}$ becomes hypoplastic or aplastic. Therefore, in some cases a well developed BCNC seen on CT with absent $\mathrm{CN}$ on MRI. ${ }^{20,31,32}$ Regarding our study, there is no data from neonatal screening to determine the exact timing of onset of HL which makes the study includes cases of acquired HL where the cochlear nerve may be injured and partially or completely degenerated leaving a normal $\mathrm{BCNC}$ in $\mathrm{CT}$.

In similar studies, when both $\mathrm{CT}$ and MRI were used together, the results were positive in $69 \%$ of cases. ${ }^{4} \mathrm{We}$ used both CT and MRI which led to a positive finding in $52 \%$ of cases with anomalies identified in one or both imaging.

\section{Conclusion:}

Pediatric USNHL can be due to inner ear anomalies. Radiological investigations are mandatory for all cases as it can identify the possible cause of HL. These valuable results over weigh the risk of radiation exposure or sedation and stresses over the fact that USNHL can be a sign of a lifethreatening condition such as the risk of 
meningitis or the possibility of progressive $\mathrm{HL}$ in the contra lateral ear.

\section{REFERENCES}

1. Friedman B, Guillory R, Ramakrishnaiah H, Frank R, Gluth MB, Richter T, Dornhoffer L: Risk analysis of unilateral severe-toprofound sensorineural hearing loss in children. International Journal of Pediatric Otorhinolaryngology. 2013; 77 (7): 11281131.

2. Yelverton J, Dominguez L, Chapman D, Wang S, Pandya A, Dodson K: Risk Factors Associated with Unilateral Hearing Loss. JAMA Otolaryngology-Head \& Neck Surgery. 2013; 139 (1):59.

3. Arndt S, Prosse S, Laszig R, Wesarg T, Aschendorff A, Hassepass F: Cochlear implantation in children with single-sided deafness: does aetiology and duration of deafness matter? Audiology \&Neurotology. 2015; 20 (1): 21-30.

4. Simons P, Mandell L, Arjmand M: Computed Tomography and Magnetic Resonance Imaging in Pediatric Unilateral and Asymmetric Sensorineural Hearing Loss. Archives of Otolaryngology-Head \& Neck Surgery. 2006; 132 (2): 186.

5. McClay E, Booth N, Parry A, Johnson R, Roland P: Evaluation of pediatric sensorineural hearing loss with magnetic resonance imaging. Archives of Otolaryngology--Head \& Neck surgery. 2008; 134 (9): 945-952.

6. Wentland C, Ronner E, Basonbul R, Pinnapureddy S, Mankarious L, Keamy D, Lee D, Cohen M: Utilization of diagnostic testing for pediatric sensorineural hearing loss. International Journal of Pediatric Otorhinolaryngology. 2018; 111:26-31.

7. Adunka F, Roush A, Teagle B, Brown J, Zdanski J, Jewells V, Buchman A: Internal Auditory Canal Morphology in Children with Cochlear Nerve Deficiency. Otology \& Neurotology. 2006; 27 (6):793801.

8. Ropers F, Pham E, Kant S, Rotteveel L, Rings E, Verbist B, Dekkers O:Assessment of the Clinical Benefit of Imaging in Children with Unilateral Sensorineural Hearing Loss. JAMA Otolaryngology-Head \& Neck Surgery. 2019; 145(5): 431.

9. Lee S, Kim S, Bae Y, Kim E, Koo J, Choi B: Appropriate Imaging Modality for the Etiologic Diagnosis of Congenital SingleSided Deafness in Children. Journal of Clinical Medicine. 2018; 7(12): 515.

10. Marx M, Costa N, Lepage B, Taoui S, Molinier L, Déguine O, Fraysse B: Cochlear implantation as a treatment for single-sided deafness and asymmetric hearing loss: a randomized controlled evaluation of cost-utility. BMC Ear, Nose, and Throat disorders.2019.

11. World health organization (WHO). Grades of hearing impairment. http://www.who. int/pbd/deafness/hearing impairment_grade s/en/. Published November 21,2017.

12. Sennaroğlu, L, Bajin, M: Classification and Current Management of Inner Ear Malformations. Balkan Medical Journal. 2017; 34(5): 397-411.

13. Davis W, Bamford J, Wilson I, Ramkalawan T, Forshaw M, Wright S:A critical review of the role of neonatal hearing screening in the detection of congenital hearing impairment.Health Technology Assessment. 1997; 1(10): i-iv, 1-176.

14. Bamford J, Uus K, Davis A:Screening for hearing loss in childhood: issues, evidence and current approaches in the UK. Journal of Medical Screening. 2005; 12(3): 119-24.

15. Calkoen V, Aliaga S, Merkus P, Smit F, Van de kamp M, Mulder F, Goverts T, HensenF: High prevalence of abnormalities on $\mathrm{CT}$ and MR imaging in children with unilateral sensorineural hearing loss irrespective of age or degree of hearing loss. International Journal of Pediatric Otorhinolaryngology. 2017; 97:185-191.

16. Sunwoo W, Lee WW, Choi BY: Extremely common radiographic finding of cochlear nerve deficiency among infants with prelingual single-sided deafness and its clinical implications. International Journal 
of Pediatric Otorhinolaryngology. 2018; 112: 176-181.

17. Ghogomu N, Nsangou T, Umansky, A, Lieu, J:Epidemiology of unilateral sensorineural hearing loss with universal newborn hearing screening. The Laryngoscope. 2014; 124 (1): 295-300.

18. Bamiou DE, Savy L, O’Mahoney C, Phelps $P$, Sirimanna T: Unilateral sensorineural hearing loss and its aetiology in childhood: the contribution of computerised tomography in aetiological diagnosis and management. International Journal of Pediatric Otorhinolaryngology. 1999; 51 (2): 91-99.

19. Levi J, Ames J, Bacik K, Darke C, Morlet $\mathrm{T}$, Oreilly C: Clinical characteristics of children with cochlear nerve dysplasias. The Laryngoscope. 2012; 123 (3): 752-756.

20. Miyasaka M, Nosaka S, Morimoto N, Taiji $\mathrm{H}$, Masaki $\mathrm{H}$ : $\mathrm{CT}$ and MR imaging for pediatric cochlear implantation: emphasis on the relationship between the cochlear nerve canal and the cochlear nerve. Pediatric Radiology. 2010; 40 (9):15091516.

21. Westerhof JP, Rademaker J, Weber P, Becker H: Congenital Malformations of the Inner Ear and the Vestibulocochlear Nerve in Children with Sensorineural Hearing Loss: Evaluation with CT and MRI. Journal of Computer Assisted Tomography. 2001; 25 (5): 719-726.

22. Song J, Choi H, Oh S, Chang S, Kim S, Lee $\mathrm{H}$ : Unilateral Sensorineural Hearing Loss in Children. Otology \& Neurotology. 2009; 30 (5): 604-608.

23. Masuda S, Usui S, Matsunaga T: High prevalence of inner-ear and/or internal auditory canal malformations in children with unilateral sensorineural hearing loss. International Journal of Pediatric Otorhinolaryngology. 2013; 77 (2) :228232.

24. Wu J, He B, Tan H, Hu P, Peng Q, Xiao A, Yang S, Wang T, Qing J, Chen $\mathrm{X}, \mathrm{Li}$ $\mathrm{K}$, Peng T, Dong P, Liu Z, Xie H: Imaging assessment of profound sensorineural deafness with inner ear anatomical abnormalities. Journal of Otology. 2015; 10 (1): 29-38.

25. Santos S, Sgambatti L, Bueno A, Albi G, Suárez A, Domínguez MJ: Enlarged vestibular aqueduct syndrome. A review of 55 paediatric patients. Acta Otorrinolaringologica (English Edition). 2010; 61(5): 338-344.

26. Shim H, Song D, Lee S, Lee D, Park J, Shin J, Kim S: A case of unilateral sensorineural hearing loss caused by a venous malformation of the internal auditory canal. International Journal of Pediatric Otorhinolaryngology.2007; 71(9): 14791483.

27. Ferreira D, Mendes V, Vide A, Costa:Developmental venous anomaly of the internal auditory canal in a child with unilateral sensorineural hearing loss- a rare association. Pediatric Radiology. 2012; 42(8): 1021-1023.

28. Papanikolaou V, Khan H, Keogh J: Incidental findings on MRI scans of patients presenting with audiovestibular symptoms. BMC Ear, Nose and Throat Disorders. 2010; 10(1). doi: 10.1186/14726815-10-6.

29. Li Y, Yang J, Liu J, Wu H: Restudy of malformations of the internal auditory meatus, cochlear nerve canal and cochlear nerve. European Archives of Oto-RhinoLaryngology. 2014; 272 (7): 1587-1596.

30. Huang B, Roche J, Buchman C, Castillo M: Brain stem and inner ear abnormalities in children with auditory neuropathy spectrum disorder and cochlear nerve deficiency. American Journal of Neuroradiology. 2010; 31(10): 1972-1979.

31. Shibata B, Budenz L, Bowling A, Pfingst E, Raphael Y: Nerve maintenance and regeneration in the damaged cochlea. Hearing research.2011; 281(1-2):56-64.

32. Chung J, Jang H, Chang O, Song J, Cho W, Kim Y, Lee H, Oh H: Does the Width of the Bony Cochlear Nerve Canal Predict the Outcomes of Cochlear Implantation? Bio Med Research International. 2018; 2018: 19. 


\section{Hassan Wahba, et al.,}

\section{تصوير العظم الصدغي في حالات فقدان السمع الحسي الشديد الى الكلى بجهة واحدة

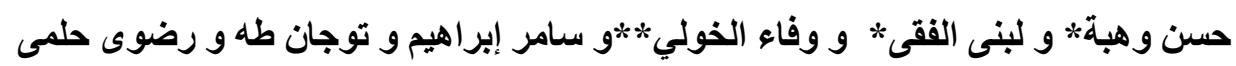

المقدمة: أوضحت دراسات عديدة تأثير ضعف السمع أحادي الجهة علي جودة حياة المرضي ولذابلك ظهرت فيرت عدة أبحاث أنعةة تحاول توضيح الأسباب التشريحية للمرض ولكن العديد منها واجة اختلافات كبيرة في نسب ظهور التشوهات

$$
\text { الهُف من البحث: تحديد نسب حدوث التشوهات المختلفة المسببة لضعف السمع. }
$$

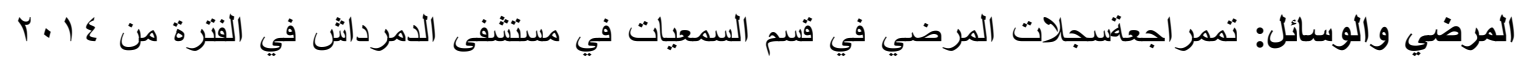

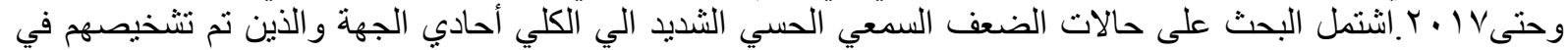

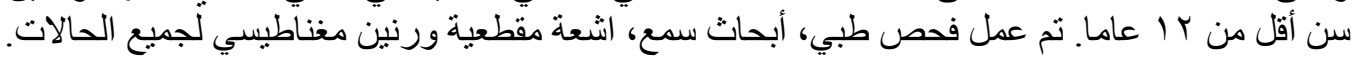

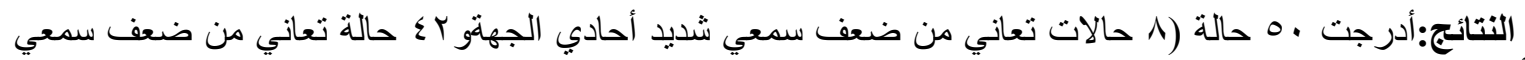

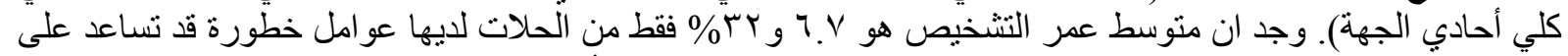

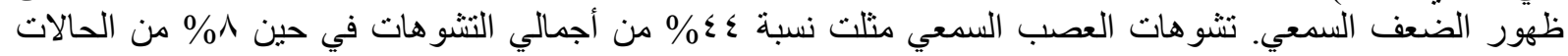
تعاني من تشو هات بالجهنين.

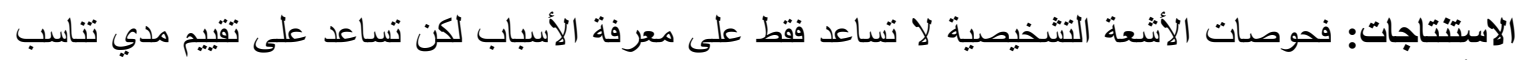
وسائل التأهيل المختلفة وشر ح المعلومات للمرضي وذوية لاتهر. 